\title{
LOS CATÓLICOS Y LAS JUBILACIONES FERROVIARIAS EN LOS INICIOS DE LA LEGISLACIÓN SOCIAL (ARGENTINA, 1912-1915)
}

\section{Catholics and railroad retirements at the beginning of social legislation (Argentina, 1912-1915)}

\author{
María Belén Portelli \\ Instituto de Estudios Históricos - \\ CONICET, Argentina
}

\begin{abstract}
Resumen: Este trabajo analiza la participación del catolicismo social en el proceso de construcción de las políticas sociales en Argentina a inicios del siglo XX, centrándose en la creación de las jubilaciones ferroviarias. Se sostiene que los diputados católicos participaron activamente en el diseño, la defensa y la aprobación del proyecto, en un juego dinámico de acuerdos y enfrentamientos con diversos sectores políticos y sociales. La propuesta, afín a los principios católicos, se convirtió en un instrumento para rivalizar con sus adversarios y extender su presencia entre los trabajadores.
\end{abstract}

Palabras clave: Argentina, legislación social, catolicismo social, ferroviarios, jubilaciones.

Abstract: This article analyses the role of Catholic social teaching in the processes of policy development in Argentina at the beginning of the 20th century, with a focus on the creation of railroad retirement benefits. It is stated that Catholic representatives actively participated in the design, advocacy, and approval of the project, in a dynamic game of agreements and confrontations with different political and social sectors. Related to Catholic principles, the proposal became an instrument they could use to compete with their adversaries and to extend their presence among workers.

Keywords: Argentina, social legislation, social Catholicism, railroads, retirements.

\section{Introducción}

A finales del siglo XIX, Argentina experimentó la emergencia de un amplio y diverso conjunto de problemáticas sociales derivadas de la expansión económi- 
ca, la explosión demográfica y el crecimiento urbano. La llamada «cuestión social» estuvo estrechamente vinculada a la situación del mundo del trabajo, pero fue a inicios del siglo xx cuando el problema obrero ganó centralidad (Suriano, 2000). El aumento de las huelgas, el avance de la organización obrera y la difusión de ideologías contestatarias generaron preocupación entre los sectores dirigentes. La radicalización del conflicto y el desarrollo de ideas reformistas socavaron paulatinamente el predominio del liberalismo clásico y promovieron una mayor intervención del Estado en el plano social (Zimmermann, 1995).

Este es el marco en el que se inscribe el presente trabajo, que forma parte de una línea de investigación de más largo alcance dedicada a estudiar el complejo proceso de construcción de las primeras políticas sociales en la Argentina de principios del siglo xx. Como un avance en ese sentido, procura indagar la participación del catolicismo en la conformación de una temprana legislación social.

Bajo el influjo de la encíclica Rerum novarum (1891), las primeras acciones del movimiento católico social se canalizaron a través de los Círculos de Obreros (CO). ${ }^{1}$ Inaugurados en 1892, se consolidaron como asociaciones mutuales interclasistas que promovieron la sanción de leyes obreras y la difusión de los valores cristianos para contrarrestar el avance de las ideologías de izquierda entre los trabajadores. ${ }^{2}$ En 1902 se fundó la Liga Democrática Cristiana, que procuró avanzar en la sindicalización obrera, aunque despertó recelos entre los católicos más conservadores y entró en crisis hacia 1907 (Di Stefano y Zanatta, 2000; Martín, 2020). Desde entonces, las autoridades eclesiásticas buscaron una mayor cohesión y moderación del movimiento católico (Di Stefano y Zanatta, 2000: 391). A partir de 1912, esta expectativa se depositó en los CO, que bajo la conducción de monseñor Miguel de Andrea y de Alejandro Bunge estrecharon sus lazos con la curia metropolitana y los grupos de poder, y asumieron un reformismo más moderado y un tono nacionalista (Martín, 2020: 134-135). Al mismo tiempo, los CO iniciaron «un plan de conquista de las masas» que contempló una mayor presencia de los trabajadores en los puestos directivos y un significativo impulso del gremialismo cristiano (Ibídem: 220). Estas transformaciones no quedaron al margen de la apertura política que el régimen conservador inauguró en 1912, que avivó el temor de los católicos por un avance electoral del socialismo y alentó sus posibilidades de orientarse hacia el partidismo y buscar la adhesión de la ciudadanía (Castro, 2011; Martín, 2020: 159-160). ${ }^{3}$

1. En este documento, León XIII reconoció la gravedad del problema obrero y condenó las respuestas del liberalismo y el socialismo. Sin dejar de apelar a la caridad, propició una mayor intervención del Estado mediante una política legislativa orientada a mejorar la situación de los trabajadores. Por esta vía, la Iglesia aspiraba a conciliar las fuerzas del trabajo y el capital y evitar estallidos revolucionarios (Recalde, 1985: 66-72).

2. Asquini (2013); Auza (1987); Lida (2015); Martín (2020); Recalde (1985); Vidal (2006).

3. A finales del siglo XIX, el régimen conservador fue impugnado por los sectores opositores que conformaron la Unión Cívica Radical (1891). Poco después, se organizó el Partido Socialista (1896). Al iniciarse el siglo xx, algunos grupos conservadores alentaron una apertura acotada, que dotara de legitimidad al sistema y les permitiera mantener el control del Estado (Cattaruza, 2016: 41). En 1912, bajo el gobierno de Roque Sáenz Peña, la voluntad reformista cristalizó en la ley electoral 8871, que 
En este contexto, los católicos cordobeses Arturo M. Bas y Juan F. Cafferata desembarcaron en la Cámara de Diputados del Congreso Nacional. Aunque tenían perfiles y adscripciones partidarias diferentes, ambos adherían al catolicismo social y durante sus mandatos, entre 1912 y 1916, promovieron numerosas iniciativas de legislación obrera. ${ }^{4}$

La labor parlamentaria de estas figuras ha sido escasamente estudiada. ${ }^{5}$ Una de las principales excepciones es Néstor Auza (1987), quien contempló sus propuestas como una objetivación y consecución del programa social cristiano. Estudios posteriores no variaron significativamente esta lectura (Lida, 2015; 2018; Portelli, 2017; Vidal, 2014). Aunque es innegable que el ideario católico informó sus intervenciones, este abordaje no resulta suficientemente explicativo de la participación de estos agentes en los procesos de construcción de las primeras leyes sociales. Por un lado, porque sus desempeños son entendidos como una transposición lineal y mecánica de los principios cristianos, lo que soslaya los intereses políticos y el papel de la contingencia, la negociación y el conflicto. Y, por otro lado, porque sus iniciativas se observan como productos endógenos de las filas católicas, sin considerar su lugar en un escenario más amplio que incluía a otros actores interesados en llevar adelante políticas reformistas.

Esta contribución busca profundizar el conocimiento sobre la actuación de estos diputados católicos en materia de legislación social. Para ello, incorpora una concepción de la arena estatal como «un espacio polifónico en el que se relacionan y se expresan grupos", lo que pone de relieve su carácter complejo, conflictivo e históricamente situado (Bohoslavsky y Soprano, 2010: 24). Esto favorece la comprensión de las políticas públicas como el resultado de dinámicas interacciones entre agentes estatales y no estatales, con racionalidades y motivaciones particulares, que contribuyen a definir su contenido y condicionan su aplicación en contextos históricos específicos.

Desde estas coordenadas, el artículo se focaliza en el proceso de creación de las jubilaciones para los trabajadores ferroviarios. Esta iniciativa se instaló en el Congreso luego de la gran huelga que foguistas y maquinistas protagonizaron en 1912. Desde entonces, siguió un largo derrotero de debates y tensiones,

estableció el voto universal masculino, secreto y obligatorio e incorporó el sistema de lista incompleta que permitía integrar a las minorías. El nuevo sistema posibilitó la representación de los sectores que anteriormente habían permanecido excluidos del juego político e incrementó los niveles de participación de la ciudadanía. Como corolario, el radical Hipólito Yrigoyen triunfó en las elecciones presidenciales de 1916.

4. Bas era Doctor en Derecho y docente de la Universidad Nacional de Córdoba. Inició su carrera política con los sectores conservadores opositores al Partido Autonomista Nacional y disputó las elecciones legislativas de 1912 como miembro de la Unión Nacional. Cafferata era médico y profesor de la universidad cordobesa, y fue elegido diputado nacional por el Partido Constitucional. Ambos eran miembros del $\mathrm{CO}$ de Córdoba y figuraron entre los candidatos que el catolicismo cordobés recomendó votar en 1912 como aquellos que garantizaban la defensa de los principios cristianos (Vidal, 2014: 29-35 y 46-55).

5. Desde la historia política, se examinó el rol de Bas en el Partido Constitucional (Castro, 2011), así como su posterior participación en el radicalismo y la inserción de Cafferata en el Partido Demócrata (Ferrari, 2008; Vidal, 1995). 
que culminó en 1915 con la sanción de la Ley 9653, que creó la primera caja de jubilaciones para un sector privado. ${ }^{6}$ Los católicos no solo apoyaron la medida, sino que además la presentaron como un resultado de la acción de sus diputados en el Congreso. Por esta razón, su gestación ofrece un mirador privilegiado para ahondar en la participación del catolicismo social en la compleja construcción de las políticas sociales.

El análisis procura establecer cómo y por qué los retiros ferroviarios conformaron una de las piezas del accionar legislativo del catolicismo social. Para ello, examina el origen de la iniciativa, la labor de los diputados católicos en el Parlamento, las ideas que desplegaron sobre derecho obrero e intervencionismo estatal, y las relaciones que establecieron con otros actores estatales y sociales, así como las lógicas e intereses que marcaron sus gestiones.

Se sostiene que la iniciativa no nació en el catolicismo social, pero los diputados católicos participaron activamente en el diseño, la defensa y la aprobación del proyecto, en un juego dinámico de acuerdos y enfrentamientos con diversos sectores del arco político, gremial y empresarial. Junto con ellos, la prensa y las asociaciones católicas sostuvieron la propuesta porque era afín a los principios del catolicismo social. Además, se convirtió en un instrumento para rivalizar con sus adversarios y extender su presencia entre los trabajadores.

El trabajo cuenta con un amplio conjunto de fuentes de diversos orígenes. Los Diarios de Sesiones del Congreso Nacional permitieron identificar a los actores que intervinieron en el origen de la ley, así como sus argumentos, acuerdos y debates. Para profundizar las posiciones y racionalidades del catolicismo se emplearon los periódicos El Pueblo, Los Principios y El Trabajo, junto con la obra de Bas, Temas Institucionales (1919).Estos materiales se complementaron con prensa gremial (La Fraternidad y El Obrero Ferroviario) y socialista (La Vanguardia).

La primera parte del artículo analiza la creación de este beneficio jubilatorio, atendiendo a la situación de los ferroviarios, el surgimiento del proyecto en un marco de conflictividad obrera y las marchas y contramarchas que siguió en el Congreso. En la segunda sección, la mirada se concentra en el rol que desempeñaron los católicos a lo largo de ese proceso.

\section{El camino hacia la Ley 9653}

Al iniciarse el siglo xx, los ferrocarriles desempeñaban un rol crucial en la economía argentina, pues transportaban las materias primas hacia los puertos para su exportación y distribuían las importaciones en el interior del país. Para 1912, la red ferroviaria alcanzaba una longitud total de 31.460 kilómetros, con lo que se posicionaba en noveno lugar entre las más extensas del mundo (Ministerio

6. La historiografía examinó los orígenes de esta ley atendiendo al interés de los sectores dirigentes en prevenir conflictos obreros (Isuani, 1985), así como su contribución al sistema de seguridad social (Flier, 2000) y su importancia en el proceso de incorporación de la vejez en la agenda social y política de comienzos del siglo xx (Otero, 2020). 
de Obras Públicas, 1918: XI). Su funcionamiento estaba a cargo de una veintena de compañías, de administración particular y estatal. En conjunto, congregaban a 122.248 trabajadores, distribuidos en una amplia diversidad de secciones y tareas, con distintas calificaciones y condiciones laborales, además de una distribución espacial diferenciada (Ibídem: 390-391).

La Ley General de Ferrocarriles Nacionales (1891) introdujo mínimas disposiciones sobre el empleo ferroviario y cada empresa tuvo un amplio margen para elaborar sus propios reglamentos de trabajo. Las compañías especificaron las responsabilidades de cada puesto y fijaron las sanciones en caso de incumplimiento con el fin de fomentar la disciplina laboral. Asimismo, implementaron suplementos salariales y programas sociales para armonizar los vínculos con su personal y promover la construcción de un sentido de pertenencia y lealtad ( $\mathrm{Pa}-$ lermo, 2004). Entre estos beneficios, algunas administraciones crearon fondos para jubilaciones. Su monto era bajo y su asignación se regía por las normas y los criterios de cada empresa. ${ }^{7}$ En consecuencia, se trataba de una concesión graciable, a menudo ligada a la arbitrariedad y la coacción (D'Uva, 2020).

En 1900, el maquinista Víctor Bassi elevó a la comisión directiva de La Fraternidad (LF) -el gremio que nucleaba a maquinistas y foguistas desde 1887- un proyecto de creación de un fondo de pensiones y jubilaciones. Con algunas modificaciones, la entidad elevó la propuesta a la Dirección General de Vías de Comunicaciones, pero las gestiones no prosperaron (Chiti y Agnelli, 1937: 194-195).

Pese a este antecedente, las jubilaciones no figuraron entre las principales reivindicaciones obreras del período, las cuales se centraron en la mejora de las condiciones laborales -aumento de salarios, reducción de jornadas, descanso semanal, seguridad e higiene en las instalaciones y protección de mujeres y niños trabajadores - . Es probable que la baja esperanza de vida -40 años - y las escasas expectativas de llegar a los 60 años propiciaran que las demandas laborales se focalizaran en las necesidades del presente y no en un futuro que parecía lejano y poco probable (Otero, 2020: 129).

El pliego de condiciones que LF presentó a las empresas a finales de 1911 no incluyó los retiros. El gremio aspiraba a obtener un reglamento general del trabajo, que pautara con uniformidad sus deberes y derechos y permitiera evitar la arbitrariedad de las compañías (Gordillo, 1988a). Ante la resistencia empresarial, en enero de 1912 los trabajadores iniciaron una huelga que perturbó el tráfico ferroviario en plena época de cosecha. El Gobierno apeló a la represión, aunque evidenció algunas actitudes conciliadoras que sugerían incipientes cambios en el rol del Estado en la regulación de las relaciones laborales (Suriano, 1991).

Tras 52 días, el conflicto culminó con un acuerdo que establecía la gradual readmisión de los huelguistas (D’Uva, 2018: 23). Además, el Gobierno se comprometió a preparar una reglamentación del trabajo que contemplara, entre

7. En el Ferrocarril del Sud se asignaban a los trabajadores de 60 años y 15 de servicio, y equivalían a un tercio del salario percibido en actividad. El Ferrocarril Central Argentino estableció que todo empleado de 55 años con 15 de servicio que no pudiera continuar trabajando recibiría una jubilación del 33\% del último salario (D’Uva, 2020: 149). 
otros tópicos, disposiciones sobre jubilaciones. ${ }^{8}$ LF recibió la noticia como la posibilidad de «librarnos de los retiros e indemnizaciones puramente graciables y más ilusorias que reales que nos concedían las compañías». ${ }^{9}$ En julio de 1912 , el gremio incorporó a sus estatutos "el establecimiento de una caja de pensiones y retiros, por parte de las empresas, para los empleados y obreros", señalando que era una de las "reivindicaciones más justificadas y urgentes». ${ }^{10}$

Esta vez, la agenda pública no desatendió la cuestión. El 3 de julio de 1912, el diputado conservador Carlos Carlés presentó un proyecto de ley que incorporaba al personal ferroviario de las empresas particulares a la Caja Nacional de Jubilaciones de los empleados estatales (creada en 1904). ${ }^{11}$ Podrían ser beneficiarios quienes tuvieran 55 años y contaran con 25 de servicios continuados. Para la formación del fondo, el Poder Ejecutivo acordaría con las empresas el monto y el origen de su contribución. Según Carlés, aunque se trataba de empleados de empresas privadas, el Estado debía garantizar su bienestar y protección porque ofrecían un servicio público cuya interrupción tenía graves consecuencias. Como planteó Ernesto Isuani (1985), era una respuesta del poder público a la reciente demostración de fuerza del sector, que buscaba descomprimir el malestar obrero y evitar el estallido de nuevos conflictos que amenazaran el funcionamiento de la economía agroexportadora.

Numerosos trabajadores remitieron telegramas al Congreso para solicitar la aprobación del proyecto. LF reclamó algunas modificaciones, aunque se mostró favorable a la iniciativa y la contempló como un fruto de su lucha. Entretanto, la recientemente fundada Federación Obrera Ferrocarrilera (FOF) - que agrupaba al personal de tráfico, talleres, vías y obras - recibió la propuesta con recelo, pues desconfiaba de los propósitos del Gobierno y consideraba que solo se trataba de una "pequeña migaja». ${ }^{12}$

La comisión de legislación estudió la iniciativa de Carlés y, a finales de 1912, presentó su despacho con un proyecto alternativo, consistente en crear una caja específica para todos los empleados y obreros de las empresas ferroviarias particulares y estatales con jurisdicción nacional. ${ }^{13}$ Sería una institución pública, financiada con aportes de los trabajadores, las compañías y el Estado, y administrada por representantes de estos tres sectores designados por el Poder Ejecutivo. ${ }^{14}$ Establecía, además, que una comisión técnica prepararía un in-

8. «La solución», El Pueblo, Buenos Aires, 28/2/1912, pág. 2.

9. "La solución del conflicto», La Fraternidad, Buenos Aires, núms. 51/54, Enero/Abril 1912, pág. 2 .

10. «Proyecto de reformas al estatuto», La Fraternidad, Buenos Aires, núm. 56, Junio 1912, pág. 6.

11. Diario de Sesiones de la Cámara de Diputados (DSCD). Congreso Nacional. Buenos Aires. Sesión 3/7/1912, págs. 535-539. Carlos Carlés fue Director General de Correos y Telégrafos (18911898) y diputado nacional por Capital (1907-1910 y 1910-1914). En 1910, participó en las manifestaciones nacionalistas que atacaron locales de prensa anarquista (Iñigo Carrera, 2013).

12. «La jubilación», El Obrero Ferroviario, Buenos Aires, núms. 7-8, Enero 1913, pág. 1.

13. $D S C D$, sesión 10/1/1913, págs. 186-188.

14. Los trabajadores contribuirían con el $5 \%$ de sus sueldos y el aporte de las empresas no podría ser inferior a ese porcentaje. Para la aportación del Estado, el proyecto creaba un impuesto a los pasajes. 
forme a partir del cual el Congreso sancionaría la ley orgánica que fijaría la edad, el tiempo de servicio y el monto de las jubilaciones según las diversas categorías de empleados y obreros. Tras largas discusiones, la propuesta de la comisión fue aprobada con ligeras modificaciones el 17 de enero de 1913.

A finales de julio, cuando el Senado estudiaba el proyecto, varias empresas ferroviarias manifestaron su oposición. En una nota dirigida a la cámara, los representantes y gerentes de las compañías plantearon que la jubilación era «un favor pecuniario», un "acto deliberado» del empleador de acuerdo a los años de servicio y «el comportamiento» del trabajador, así como la situación financiera de la empresa. ${ }^{15}$ Negaron la injerencia del Estado en la materia: «no hay una ley ni puede haberla, que obligue a las personas a jubilar a sus empleados, ni mucho menos a fijar las condiciones de servicio y de retribución $\gg .{ }^{16}$ Agregaron que el aporte fijo del $5 \%$ arruinaría a las firmas de menores ganancias e implicaría un incumplimiento de la ley Mitre (1907), que las exoneraba de cualquier impuesto a cambio de un pago único del $3 \%$ de sus utilidades.

El 9 de septiembre de 1913, el Senado sancionó el proyecto con importantes modificaciones. ${ }^{17}$ Se suprimió la dependencia estatal de la caja para convertirla en una entidad autónoma, sobre la cual el Estado solo podría ejercer funciones de superintendencia. El personal de los ferrocarriles estatales fue excluido del beneficio, bajo la premisa de que sus jubilaciones ya estaban garantizadas por la Caja Nacional. El aporte de los trabajadores y las empresas disminuyó al 3\% y el impuesto a los pasajes fue sustituido por un derecho sobre los fletes de cargas y encomiendas. Por último, el senador Salvador Maciá propuso agregar un artículo (número 11) que estableciera que los trabajadores que abandonaran voluntariamente el servicio, perturbando o interrumpiendo la regularidad de los ferrocarriles, serían apartados y perderían todo derecho a la jubilación. El senador socialista Enrique del Valle Iberlucea rechazó la propuesta por considerar que implicaba una restricción del derecho a huelga de los trabajadores; por su parte, el Poder Ejecutivo respaldó a Maciá con el argumento de que era necesario evitar los conflictos que alteraban la marcha de los ferrocarriles. Tras arduos debates, el artículo fue aprobado con un añadido que habilitaba a la administración de la caja a actuar como tribunal arbitral y resolver si el abandono del servicio se había producido por causas justificadas.

LF cuestionó el artículo 11 e instó a los diputados a insistir en su sanción primitiva. ${ }^{18}$ Por su parte, la FOF alentó la movilización contra el proyecto porque establecía un descuento compulsivo sobre los salarios y «nos impide cualquier

15. Diario de Sesiones de la Cámara de Senadores (DSCS). Congreso Nacional. Buenos Aires. Sesión 26/8/1913, pág. 809.

16. Idem.

17. DSCS, sesión 26/8/1913, págs. 811-838; sesión 28/8/1913, págs. 843-859; sesión 2/9/1913, págs. 862-884; sesión 4/9/1913, págs. 886-912; sesión 6/9/1913, págs. 916-944; sesión 9/9/1913, págs. 950-972.

18. «Las jubilaciones ferroviarias», La Fraternidad, Buenos Aires, núm. 85, 15/9/1913, pág. 1. 
acto de defensa». ${ }^{19}$ Sin embargo, no faltaron trabajadores que reclamaron una pronta sanción del proyecto con el artículo 11 incluido.

En 1914, la comisión de legislación de la Cámara de Diputados emitió un dictamen dividido: la mayoría aconsejó la aprobación de las modificaciones del Senado, mientras que una minoría se pronunció en contra del artículo $11 .{ }^{20} \mathrm{El}$ asunto no recibió tratamiento hasta 1915. Luego de una incidencia de caducidad que demoró brevemente su consideración, los diputados discutieron sobre las modificaciones del Senado y, especialmente, sobre el artículo 11, que resultó aprobado con 35 votos a favor y 30 en contra, con lo que la Ley 9653 quedó sancionada el 21 de junio de 1915. Esta ley creaba una Caja de Jubilaciones y Pensiones para empleados y obreros permanentes de los ferrocarriles de empresas particulares de jurisdicción nacional. Su capital se formaría con el descuento del $3 \%$ de los sueldos, una contribución de las empresas no inferior al $3 \%$ y los fondos derivados de los aumentos en los fletes. Además, una comisión técnica reuniría información para fijar las condiciones y el monto de las jubilaciones en una futura ley orgánica. ${ }^{21}$

\section{Los católicos y las jubilaciones ferroviarias}

El análisis de la participación de los diputados católicos en el proceso de creación de las jubilaciones ferroviarias permite identificar dos momentos. El primero, entre la presentación de la propuesta de Carlés y la primera sanción de la Cámara de Diputados, estuvo marcado por un visible protagonismo de Arturo M. Bas en el diseño y la defensa del proyecto alternativo de la comisión de legislación, que recogía los planteamientos de LF y establecía acuerdos con otros sectores del reformismo social, incluido el socialismo. Las modificaciones incorporadas por el Senado (especialmente, el artículo 11) inauguraron una segunda etapa, caracterizada por el fin de la convergencia con los socialistas y el despliegue de una disputa que trascendía las motivaciones ideológicas.

\subsection{Consensos reformistas (1912-1913)}

Tras incorporarse a la Cámara de Diputados, en junio de 1912, el católico Bas integró la comisión de legislación junto con figuras del conservadurismo (Ernesto Padilla, Adrián Escobar, Jerónimo del Barco, Guillermo Rothe y Julio Terán), el radicalismo (Vicente Gallo) y el socialismo (Alfredo Palacios).

Esta comisión estuvo encargada de estudiar la factibilidad y las posibles consecuencias del proyecto de Carlés. Para ello, recabó los pareceres del pre-

19. «Contra la jubilación», El Obrero Ferroviario, Buenos Aires, núm. 15, Noviembre 1913, pág. 1. 20. $D S C D$, sesión 4/6/1915, pág. 297.

21. La ley fue reglamentada el 1 de septiembre de 1915. Aunque los trabajadores percibieron los descuentos para la formación del fondo, el beneficio no se efectivizó hasta 1919, cuando se aprobó la ley orgánica de la Caja de Jubilaciones Ferroviarias (10650). 
sidente de la Caja Nacional de jubilaciones, quien sugirió no involucrar al personal de las empresas particulares en el régimen jubilatorio de los empleados estatales y crear una caja específica para los ferroviarios de las compañías privadas. ${ }^{22}$ La comisión tomó en cuenta esta propuesta, especialmente porque los datos financieros de la Caja Nacional registraban un descenso sostenido y hacían presumir que la entidad se encaminaba a una crisis. ${ }^{23}$

LF también presentó sus observaciones. ${ }^{24}$ El gremio cuestionó la aplicación del límite de edad que regía para los empleados públicos (55 años), pues los ferroviarios trabajaban desde muy jóvenes en labores que implicaban un gran desgaste físico. También solicitó que se computaran los años de servicios en las distintas compañías, que el personal fuese eximido de contribuir con sus salarios, que se consideraran las diferencias entre el personal viajante y el sedentario, y que el valor de la pensión se estableciera según el salario percibido al momento del retiro.

Finalmente, la comisión de legislación resolvió desestimar la propuesta de Carlés y elaborar un anteproyecto alternativo. Bas y Gallo integraron la subcomisión designada para ese fin. ${ }^{25}$ Ambos diputados mantuvieron reuniones con los empresarios y advirtieron que estos rehusaban explicar cómo contribuirían a la caja. En consecuencia, consideraron que la fórmula de Carlés no garantizaba el aporte de las compañías y resolvieron establecer un porcentaje fijo de contribución sobre sus ganancias, igual al descuento salarial de los empleados $(5 \%) .{ }^{26}$ Propusieron, además, la creación de un impuesto a los pasajes para contribuir al fondo.

El anteproyecto de la subcomisión estuvo listo a finales de noviembre de 1912. Las empresas rechazaron sus condiciones y manifestaron que se adherían a la iniciativa de Carlés y estaban dispuestas a convenir con el Gobierno el modo en que contribuirían al fondo. ${ }^{27}$ En contraposición, la prensa socialista celebró el contenido del anteproyecto y reconoció los «grandes esfuerzos» de la subcomisión, al tiempo que cuestionó la actitud de las compañías: «Quieren que el público o el gobierno paguen todo el importe de las pensiones para los hombres que ellas [las compañías] han exprimido durante años». ${ }^{28}$ El diario católico El Pueblo elogió la actuación de Bas, señalándolo como el diputado que había defendido la importancia de esa ley en el seno de la comisión. ${ }^{29}$

Cuando la comisión de legislación consideró el anteproyecto, incorporó una demanda de LF relativa a la inclusión del personal de los ferrocarriles de juris-

22. DSCD, sesión 15/1/1913, págs. 237-238.

23. Ibídem, pág. 191.

24. «Proyecto de jubilaciones y pensiones», La Fraternidad, Buenos Aires, núm. 65, 15/11/1912, págs. 1-2.

25. En las elecciones legislativas de 1912, Gallo fue uno de los candidatos a diputados por la Capital Federal que el catolicismo sugirió elegir. Ver «La asamblea de anoche», El Pueblo, Buenos Aires, 26/3/1912, pág. 2.

26. $D S C D$, sesión 10/1/1913, págs. 199-200.

27. DSCD, sesión 16/12/1912, pág. 145.

28. «Nuestras pensiones obreras», La Vanguardia, Buenos Aires, 20/11/1912, pág. 1.

29. «La jubilación de los ferroviarios», El Pueblo, Buenos Aires, 21/11/1912, pág. 2. 
dicción provincial entre los beneficiarios. ${ }^{30}$ Para acrecentar el fondo, se dispuso una retención de la mitad del primer sueldo mensual de los empleados. El socialista Palacios expresó los reclamos de LF sobre este nuevo aporte y la comisión acordó que el descuento se efectuara paulatinamente. Además, Palacios solicitó que se incluyeran a los obreros que trabajaban a jornal, lo cual fue contemplado. ${ }^{31}$ Con estas modificaciones, el proyecto recibió el apoyo unánime de los miembros de la comisión y fue despachado a la Cámara de Diputados a mediados de diciembre.

Al iniciarse el tratamiento, Bas se desempeñó como miembro informante y argumentó a favor del proyecto alternativo. El católico señaló que la medida tenía un propósito «altamente humanitario", pues buscaba asegurar el descanso del trabajador después de muchos años de labor. ${ }^{32}$ Reconoció también que el mejoramiento de la situación obrera perseguía un fin preventivo, consistente en eliminar las causas que motivaban el estallido de conflictos. Se alineaba así con el espíritu de la Rerum novarum, que instaba a emplear las leyes para «poner remedio, lo mejor que sea posible, a las necesidades de los obreros" y conseguir la concordia en la relación trabajo-capital, o al menos «quitarle toda aspereza y hacerla así más suave» (León XIII, 1960 [1891]: 12-13).

Esta preocupación por el orden social era compartida por católicos y liberales reformistas, aunque no por los socialistas. De todos modos, no se traducía en ninguna disposición represiva contra las huelgas, lo que ayuda a comprender el apoyo socialista al proyecto. Durante el debate, el ministro de Obras Públicas, Ezequiel Ramos Mejía, sugirió que se incluyera una prohibición del derecho a huelga de los ferroviarios. Los diputados socialistas se opusieron y reivindicaron la importancia del proyecto en los términos aprobados por la comisión. Según el socialista Juan B. Justo, era «la primera de una serie de leyes semejantes, que alcanzarán en su acción a muchos gremios, y que es de desear que pronto alcancen a la totalidad de los trabajadores argentinos».33

La promoción de la acción estatal para resolver el problema obrero fue un punto de confluencia entre los católicos sociales y las distintas vertientes reformistas. En este sentido, Bas denunció las prácticas empresariales en materia de retiros: los montos eran bajos, llegaban a edad avanzada y los directorios los asignaban «a su antojo». ${ }^{34}$ Las jubilaciones no podían continuar siendo un acto graciable o una simple medida asistencial. La institucionalización de los retiros y la contribución obligatoria de las empresas apuntaban al reconocimiento de un derecho, garantizado por el Estado. Bas defendió entonces la creación de una caja de jubilaciones para el sector ferroviario como una institución estatal, cuyo funcionamiento se regulara por un dispositivo legal específico. Propiciaba así un deslizamiento desde la prescindencia hacia una mayor intervención del Estado

30. «Las jubilaciones», La Fraternidad, Buenos Aires, núm. 66, 1/12/1912, pág. 2.

31. "Congreso", La Vanguardia, Buenos Aires, 10/12/1912, pág. 1; «Las jubilaciones». La Fraternidad, Buenos Aires, núm. 67, 15/12/1912, págs. 1-2.

32. $D S C D$, sesión 10/1/1913, pág. 188.

33. $D S C D$, sesión 15/1/1913, pág. 223.

34. $D S C D$, sesión 15/1/1913, pág. 239. 
en un ámbito que las empresas percibían como propio. Este punto fue resistido por los defensores de la ortodoxia liberal, quienes aseguraron que la intervención estatal implicaría un aumento del gasto público y, peor aún, una intromisión en el dominio privado (Frers, 1921: 266).

Además de crear la caja de jubilaciones y definir quiénes serían sus beneficiarios, el proyecto disponía el nombramiento de una comisión técnica que reuniría información para la sanción de una ley orgánica. El diputado Bas justificó este desdoblamiento aludiendo a la necesidad de asentar la legislación en un cuidadoso estudio previo:

[...] es absolutamente indispensable que sus disposiciones estén basadas en factores perfectamente conocidos y precisos, en deducciones formuladas [...] con reglas de técnica científica y de principios consagrados: tablas de mortalidad, desarrollo progresivo del número de empleados, escala de sueldos, en fin, todo el conjunto de los factores que necesariamente intervienen en su complejo organismo. ${ }^{35}$

A partir de la cuantificación de estos fenómenos, podría elaborarse una legislación que estableciera la edad del retiro, los años de servicio requeridos y el monto de la jubilación según las diversas categorías de empleados y obreros. Esta postura se inspiraba en la experiencia de las naciones europeas y asumía también el principio de «saber para prever» del reformismo social, que legitimaba el empleo de conocimientos especializados como sustento de la política social. Los partidarios del proyecto de Carlés juzgaron la medida como una dilatación o postergación del beneficio. En respaldo del criterio de la comisión, Ernesto Padilla explicó que este proceder era «la única vía» para asegurar «una legislación eficaz». ${ }^{36}$

La Cámara de Diputados aprobó el proyecto de la comisión. Con ello, Bas -quien para entonces acrecentaba su proyección en el movimiento católico con su reciente designación como vicepresidente de los $\mathrm{CO}$ - registraba su primer resultado favorable en materia de legislación social. El Pueblo destacó que su correligionario había «colaborado activamente en primera línea» en el diseño y la defensa del proyecto. No lo había hecho en soledad. LF celebró que el texto había consultado y recogido los intereses de los trabajadores del riel. ${ }^{37}$ También había contado con el apoyo unánime de los miembros de la comisión, algunos de los cuales - como el radical Gallo y el socialista Palacios - participaron activamente en su redacción.

\subsection{La mecha de la discordia (1913-1915)}

Las modificaciones introducidas por el Senado pusieron fin a la convergencia entre católicos y socialistas en torno a las jubilaciones ferroviarias. Aunque am-

35. DSCD, sesión 10/1/1913, pág. 189.

36. Ibídem, pág. 203.

37. «Las jubilaciones», La Fraternidad, Buenos Aires, núms. 69-70, 1/2/1913, pág. 3. 
bos sectores apoyaban la creación de una institución de seguridad social, el artículo 11 desnudó sus diferencias ideológicas y activó la confrontación.

Mientras que el socialismo se opuso a la medida porque consideraba que restringía el derecho a huelga de los trabajadores, el catolicismo propició su aprobación. Evidentemente, el nuevo artículo era compatible con la preocupación católica por la conciliación de clases y el mantenimiento del orden social. La jubilación representaba "un acto de verdadera justicia» que ampararía a un gremio que "contribuye a la riqueza nacional» y "constantemente tiene expuesta la vida». ${ }^{38}$ Paralelamente, reportaría un beneficio para el capital, porque alejaría el peligro de las huelgas y garantizaría el funcionamiento del transporte en los momentos de cosecha. ${ }^{39}$ Se perfilaba, entonces, como una ley de «equilibrio» entre las partes, que evitaría conflictos y contribuiría a la armonía social. ${ }^{40}$

Aunque estas razones ideológicas estuvieron en la base del apoyo del catolicismo a la nueva versión del proyecto, su auspicio no careció de intereses políticos y propagandísticos. De hecho, la disputa por las jubilaciones ferroviarias puso en escena una competencia con el socialismo por las leyes protectoras de los trabajadores.

Cuando se hizo evidente que los diputados no tratarían el proyecto en el período de 1913, la prensa católica responsabilizó a los socialistas de dilatar la sanción. El diario católico cordobés Los Principios señaló que la resistencia socialista al artículo 11 privaba a los trabajadores de las jubilaciones y terminaba favoreciendo a las empresas, buscando mostrar las incoherencias de un partido que «debería ser el más interesado en obtener este beneficio si es sincero en su propaganda en favor de la clase obrera».. ${ }^{41}$ En el mismo sentido, la crónica de El Trabajo -órgano de los CO- afirmó que LF y los socialistas habían creado «una mala atmósfera» contra el proyecto, y afirmó «que son tan obstruccionistas como cualquiera de las empresas". ${ }^{42}$

Paralelamente, los medios católicos marcaron los esfuerzos de sus correligionarios para que las jubilaciones ferroviarias se convirtieran en una realidad para los trabajadores. Señalaron especialmente los méritos de Bas, a quien comenzaron a presentar como el autor y principal promotor del proyecto. En este sentido, El Pueblo expresó:

[...] el proyecto primitivo fue exhumado del olvido por el diputado Bas, que lo estudió y modificó y consiguió hacerlo despachar por la comisión de legislación de la Cámara de Diputados; que lo defendió ante ésta hasta su sanción y que, pasado al Senado, no dejó un solo instante de interesar en favor del mismo, ya directa, ya indirectamente, la buena voluntad de los miembros de la alta cámara. ${ }^{43}$

38. «Jubilación de ferroviarios», El Trabajo, Buenos Aires, Mayo 1914, pág. 2.

39. «Los ferroviarios», El Pueblo, Buenos Aires, 8/7/1914, pág. 2.

40. "Jubilación de los ferroviarios", El Pueblo, Buenos Aires, 18/11/1914, pág. 1.

41. "La jubilación de los empleados ferroviarios", Los Principios, Córdoba, 23/9/1913, pág. 2.

42. «La jubilación de los ferrocarrileros», El Trabajo, Buenos Aires, Noviembre 1913, pág. 11.

43. «La prueba de los hechos», El Pueblo, Buenos Aires, 13/9/1913, pág. 2. 
De modo similar a lo observado por María Pía Martín (2020) en la relación católicos-socialistas en el campo sindical, lo que parecía subyacer en esta disputa por la legislación social era el interés por la supremacía del propio proyecto ideológico en un terreno de acción común. En octubre de 1913, luego de la peregrinación anual a Luján, los CO marcharon al Congreso para presentar un petitorio reclamando la aprobación de los proyectos de Bas y Cafferata. El retiro de los empleados del riel fue incluido entre las piezas legislativas promovidas por el catolicismo social. ${ }^{44}$ Durante la movilización, se alzaron carteles con demandas y consignas, entre las que pudo leerse: «Queremos la jubilación de los ferroviarios». ${ }^{45}$ El director de El Pueblo, Isaac Pearson, señaló que la manifestación buscaba visibilizar la presencia católica en las calles y dar a conocer que «algo hemos hecho ya, este mismo año, en el sentido del bien general». ${ }^{46}$ Aseguró que Bas y Cafferata eran responsables de «la parte más seria de la labor legislativa del año" y que habían superado al grupo parlamentario socialista, "que se pretende intérprete exclusivo en el Congreso de las necesidades del pobre y del obrero». Por su parte, Bas expresó que el socialismo solo buscaba la destrucción del orden social, por lo que era necesario "descorrer la venda que cubre los ojos del obrero" y mostrarle que su mejoramiento provendría de «los hombres de ideas conservadoras». ${ }^{47}$ Mientras tanto, La Vanguardia denunció la connivencia del catolicismo con la clase propietaria, calificó de «mediocres» ${ }^{48}$ las iniciativas de Bas y Cafferata, y cuestionó el hecho de que pretendieran aparecer como los «verdaderos defensores de la clase obrera, como los únicos y desinteresados apóstoles de los pobres». 49

Esta confrontación no se sustrajo del nuevo escenario político inaugurado por la ampliación del sufragio y los esfuerzos del catolicismo por responder a los desafíos del proceso de democratización inaugurado en 1912. Con la llegada de monseñor Miguel de Andrea y de Alejandro Bunge a los puestos directivos de los $\mathrm{CO}$, estos organismos pretendieron ganar posiciones entre los trabajadores (Martín, 2020: 220). A la par, la reforma electoral fortaleció las posiciones parlamentarias del socialismo y amplió sus posibilidades de concretar sus propuestas, lo que fue visto por el catolicismo como una grave amenaza para el orden social. ${ }^{50}$ Estos temores jugaron un rol clave en la incursión de los católicos

44. El petitorio también solicitaba la sanción de los proyectos de ley de protección del salario, accidentes del trabajo, represión del alcoholismo, casas para obreros, reglamentación del trabajo a domicilio y protección al ahorro en las ventas por mensualidades. «La grandiosa demostración del domingo". El Pueblo, Buenos Aires, 14/10/1913, pág. 3.

45. Idem.

46. «La manifestación del domingo», El Pueblo, Buenos Aires, 7/10/1913, pág. 2.

47. Ibídem, 8/10/1913, pág. 2.

48. «La reacción negra», La Vanguardia, Buenos Aires, 8/10/1913, pág. 1.

49. «Clericalismo militante», La Vanguardia, Buenos Aires, 12/10/1913, pág. 1.

50. En 1912, el Partido Socialista obtuvo dos bancas en la Cámara de Diputados; en 1913 incorporó dos diputados más y en 1914 conquistó un total de nueve posiciones. El Senado tampoco permaneció ajeno al avance socialista, pues Enrique del Valle Iberlucea se convirtió en senador en 1913 (Camarero y Herrera, 2005: 17). 
en el Partido Constitucional. Constituida en noviembre de 1913, la agrupación contó con la dirección de Bas y definió un programa que combinó el catolicismo social con elementos nacionalistas, marcando claramente las líneas divisorias con los socialistas: Dios, patria, familia y propiedad (Castro, 2011: 8). Sus propuestas contemplaron la introducción de una legislación social orientada a «mejorar la clase obrera, pero respetando el capital», en una fórmula que buscaba contraponerse a las transformaciones revolucionarias que los dirigentes católicos asociaban al socialismo. ${ }^{51}$

Ante las elecciones legislativas de 1914, la campaña del flamante Partido Constitucional apeló a las leyes sociales promovidas por Bas y Cafferata para ampliar sus bases de apoyo y afirmar su presencia política. El proyecto de jubilaciones ferroviarias se incorporó a la propaganda partidaria para mostrar la capacidad de los católicos de responder a las necesidades de los trabajadores. En un acto proselitista, el constitucional Ramón Parborell señaló que el interés del partido en el mejoramiento obrero había motivado la elección del «joven legislador del retiro ferroviario» como su presidente..$^{52}$ Un aviso del comité partidario de San Carlos Sur definió a la agrupación como «el Partido de los Obreros», e instó a votarlo porque sus dirigentes «ya nos dieron en parte y pidieron en otra a las cámaras» una serie de iniciativas, entre las que se incluían las jubilaciones ferroviarias. ${ }^{53}$ La Vanguardia llegó a denunciar que, en sus impresos de propaganda electoral, los «clérico-constitucionales» se jactaban de haber hecho aprobar el proyecto y acusó al «jesuita Bas» de hacer campaña en complicidad con las empresas de ferrocarril, entregando manifiestos a los gerentes de las compañías para que estos los repartieran entre sus empleados. ${ }^{54}$

Es probable que, para los católicos, ganar predicamento entre los ferroviarios adquiriera una relevancia especial. La importancia estratégica de estos trabajadores en la economía agroexportadora y su dispersión en todo el territorio potenciaba los temores de que asumieran posiciones extremas y revolucionarias. Además, muchos dirigentes de LF se habían adherido al socialismo o mantenían estrechas relaciones con el partido (Gordillo, 1988b).

A instancias del proyecto jubilatorio, los católicos estrecharon sus vínculos con estos trabajadores, particularmente con aquellos que asumieron un posicionamiento diferente a LF y la FOF. Estos ferroviarios procuraban que los diputados aprobaran las modificaciones del Senado y la ley quedase sancionada lo antes posible. Denunciaban que la demora del Congreso era aprovechada por las empresas, que despedían a los trabajadores más próximos a jubilarse en caso de aprobarse la ley. Negaban sentirse amenazados por el artículo 11, porque «cuando en realidad una huelga esté plenamente justificada, los huelguistas no perderán los derechos que les acuerda la ley».55 Organizados en la Junta Nacio-

51. «La nueva fuerza católica», El Pueblo, Buenos Aires, 5/11/1913, pág. 2.

52. «Partido Constitucional», El Pueblo, Buenos Aires, 19/2/1914, pág. 2.

53. «Movimiento político», El Pueblo, Buenos Aires, 1/3/1914, pág. 3.

54. «Los cléricoconstitucionales y las empresas extranjeras», La Vanguardia, Buenos Aires, 22/3/1914, pág. 3.

55. «Jubilaciones de ferroviarios», Los Principios, Córdoba, 1/11/1913, pág. 3. 
nal Pro Jubilación, formaron subcomisiones en el interior del país con el «único y exclusivo fin de activar y gestionar de los poderes públicos de la Nación la definitiva y pronta sanción del proyecto actualmente en poder de la H. Cámara de Diputados».5 ${ }^{56}$ Según La Vanguardia, era Bas quien operaba tras ellos, pues «busca, por todos los medios a su alcance, el apoyo necesario para obtener la sanción definitiva de ese verdadero engendro antiobrero». ${ }^{57}$ El propio Bas relató:

Fue tan frecuente nuestro trato, y tan armónicas mis visitas con la enunciada comisión respecto a la anhelada ley de retiros, que llegué a identificarme con sus miembros en el propósito y en la adopción de todas las medidas conducentes a su realización (Bas, 1919: 305-306).

Es probable que la confluencia de intereses y perspectivas en torno a la cuestión haya propiciado una relación de cooperación y beneficio mutuo. Para los ferroviarios, el diputado podía brindar orientación sobre cómo presionar a las autoridades; pero también era, ante todo, un baluarte de su causa en el Congreso. A la vez, los petitorios de estos empleados contribuían a legitimar el proyecto y respaldar a los diputados que buscaban su aprobación.

En julio de 1914, Bas y Cafferata suscribieron el dictamen de la mayoría de la comisión de legislación que aconsejaba admitir las modificaciones introducidas por el Senado. ${ }^{58}$ En los meses siguientes, Bas presentó mociones de preferencia argumentando que el proyecto ya contaba con dos sanciones y existía «un verdadero clamor de parte de los empleados de ferrocarriles a este respecto». .99

Cuando la cámara se dispuso a iniciar su tratamiento, en junio de 1915, se suscitó una controversia sobre la caducidad del proyecto. Bas fue uno de los diputados que más firmemente negó que hubiera caducado y desplegó interpretaciones legales sobre el trámite de las iniciativas parlamentarias. Señaló, además, que se trataba de un asunto de interés público y de "estricta justicia» que exigía una pronta resolución. ${ }^{60}$ Aunque el socialista Alfredo Palacios coincidió con la postura, La Vanguardia criticó el discurso de Bas y buscó refutar su obrerismo: «ha encontrado en el proyecto de jubilación de obreros ferroviarios la pieza predilecta de su organito. Le sirve para interesarse de una manera platónica de [sic] los trabajadores». .1

Cuando la incidencia quedó resuelta a favor de la vigencia del proyecto, Bas actuó como miembro informante de la mayoría y sostuvo que las modificaciones del Senado no afectaban fundamentalmente el concepto del proyecto original y que era preciso satisfacer con celeridad los anhelos de los ferroviarios. ${ }^{62}$

56. «Jubilación de ferroviarios», Los Principios, Córdoba, 12/6/1914, pág. 3.

57. "Las empresas ferroviarias y la jubilación de sus obreros», La Vanguardia, Buenos Aires, 20/11/1913, pág. 1.

58. DSCD, sesión 4/6/1915, pág. 297. Los acompañaron legisladores radicales (Celestino I. Marcó, Tomás de Veiga) y conservadores (Adrián Escobar y Rainerio Lugones Vieyra).

59. $D S C D$, sesión 9/9/1914, pág. 177.

60. $D S C D$, sesión 4/6/1915, pág. 296.

61. «Congreso», La Vanguardia, Buenos Aires, 5/6/1915, pág. 1.

62. $D S C D$, sesión 9/6/1915, pág. 373. 
En relación con el artículo 11, aseguró que la medida no calificaba como delito el abandono del servicio ni establecía una penalidad para la huelga, sino que aludía a la "cesación voluntaria del contrato de trabajo» y a las "obligaciones correlativas» derivadas de la relación contractual. Este argumento fue especialmente combatido por el socialista Enrique Dickmann, quien negó la existencia de un contrato entre dos partes en desigualdad de condiciones, a lo que Bas replicó que este era un criterio doctrinario del socialismo, que «reclama todos los derechos, sin reconocer absolutamente las obligaciones».63

Para defender su postura, Bas sostuvo que «la inmensa mayoría» de los ferroviarios respaldaba la sanción del Senado, lo que se evidenciaba en la «infinidad de solicitudes» remitidas a la cámara con «miles y miles de firmas». Aseguró que los opositores al artículo 11 eran los maquinistas y foguistas de LF, numéricamente inferiores y predominantemente extranjeros. ${ }^{64}$ En consecuencia, consideraba injusto que, para salvar «un concepto general relativo a la huelga», se perjudicara a «tantos empleados ferroviarios que comprenden bien la enorme ventaja que significaría para ellos y sus familias llegar a conseguir esta ley». 65 La bancada socialista señaló que solo apoyaban el proyecto los altos empleados cercanos a los intereses patronales y una minoría de los ferroviarios en edad y condiciones de jubilarse. Denunció, además, maniobras empresariales en la elaboración de algunas peticiones y abultamientos en la cuantificación de las firmas a favor.

Bas apeló, además, a los antecedentes internacionales. Aseveró que el artículo 11 no iba más allá de lo establecido en otros países y, comparativamente, era una de las legislaciones «más benignas», pues solo creaba responsabilidades de orden civil. ${ }^{66}$ El radical Rogelio Araya apoyó este argumento y enumeró las leyes extranjeras que sancionaban la huelga ferroviaria como delito. Para exponer las contradicciones del socialismo y deslegitimar sus argumentos, ambos diputados apelaron recurrentemente a las restricciones implantadas en Australia, un país admirado por los socialistas por las reformas sociales impulsadas por el laborismo. En el mismo sentido, recuperaron los conceptos de políticos franceses de tendencias socialistas -como Georges Clemenceau y Aristide Briand- que, sin desconocer el derecho de los ferroviarios a declararse en huelga, no los eximían de responsabilidades de orden civil.

Cafferata también tomó la palabra en el debate. Afirmó que se preocupaba sinceramente por los trabajadores, sin embargo, a diferencia de los socialistas, no se titulaba representante de los obreros, sino del pueblo de la nación. Defendió el derecho a huelga como «medio lícito de defensa en los casos extremos", pero respaldó el artículo 11 porque, en el caso de los servicios públicos, era ne-

63. DSCD, sesión 14/6/1915, pág. 454.

64. En 1914, el personal empleado en los ferrocarriles ascendía a 120.557 individuos, de los cuales $21.113(17,5 \%)$ eran maquinistas y foguistas, la mitad de ellos extranjeros. A nivel nacional, se estima que el número de socios de LF ascendía a 9.500, lo que representaba un $45 \%$ del total de maquinistas y foguistas de la época (Gordillo, 1988a: 40-41).

65. $D S C D$, sesión $21 / 6 / 1915$, pág. 573.

66. $D S C D$, sesión 9/6/1915, pág. 375 . 
cesario crear ciertas limitaciones que protegieran «los altos intereses del país».67 Aseguró, además, que la comisión arbitral ofrecía garantías para los trabajadores que reclamaran por causas justificadas. Expresaba, así, la doctrina católica que admitía las huelgas «justas» y «legítimas», motivadas por reivindicaciones laborales, en contraposición a las huelgas "doctrinarias» o «revolucionarias», realizadas con fines ideológicos (Martín, 2020: 91).

Finalmente, el artículo 11 fue aprobado con 17 votos del conservadurismo y 18 de la Unión Cívica Radical. La Vanguardia lanzó sus invectivas contra esta mayoría conservadora-radical, aunque centró sus críticas en el accionar del radicalismo en materia obrera. ${ }^{68}$

Los católicos celebraron la sanción de la Ley 9653. Los CO felicitaron a Bas y Cafferata, a quienes declararon «dignos representantes del pueblo y de los más vitales intereses de nuestra causa». ${ }^{69}$ Los diarios católicos presentaron a Bas y Cafferata como «paladines esforzados» de la iniciativa, aunque el primero fue señalado como el «autor de esta ley beneficiosa» y el segundo, como su «diligente y eficaz» colaborador. ${ }^{70}$ Reprodujeron, además, las notas de agradecimiento de los ferroviarios, que reconocían a Bas como «gran leader» de la causa y responsable fundamental de la ley. ${ }^{71}$ El propio Bas reivindicó su papel protagónico:

Tres años de labor y de luchas incesantes, en el recinto de la cámara, en el seno de las comisiones, ante el poder ejecutivo o en mi gabinete de estudio, acaban de recibir su recompensa con la sanción de la ley de jubilación de ferroviarios, primera de asistencia social acordando retiros, dictada por el congreso de la nación. ${ }^{72}$

\section{Reflexiones finales}

Este trabajo ha indagado el proceso de creación de las jubilaciones ferroviarias con el propósito general de profundizar el conocimiento sobre el rol del catolicismo social en la construcción de políticas sociales en Argentina a comienzos del siglo XX.

Si se tomara como punto de partida el final de esta historia (la sanción de la Ley 9653), la lectura de las fuentes católicas induciría a pensar que se trató de un producto exclusivo del accionar de Bas y Cafferata en el Congreso, en una eficaz traducción y concreción de los principios del catolicismo social. Se reproducirían, así, las visiones más tradicionales de la historiografía sobre la práctica

67. DSCD, sesión 14/6/1915, pág. 489.

68. «El voto de ayer», La Vanguardia, Buenos Aires, 22/6/1915, pág. 1; «Revuelta y huelga». La Vanguardia, Buenos Aires, 23/6/1915, pág. 1.

69. «Acción social cristiana», El Pueblo, Buenos Aires, 16/7/1915, pág. 3.

70. Idem; «Jubilación de ferroviarios», El Pueblo, Buenos Aires, 1/7/1915, pág. 2; «Las jubilaciones ferroviarias», Los Principios, Córdoba, 5/10/1915, pág. 5; «El Dr. Juan F. Cafferata». El Pueblo, Buenos Aires, 11/11/1915, pág. 2.

71. «Los ferroviarios y sus jubilaciones», Los Principios, Córdoba, 24/6/1915, pág. 4; «Los empleados ferroviarios de la empresa del Oeste», El Pueblo, Buenos Aires, 21/7/1915, pág. 2.

72. «En honor del Dr. Bas», El Pueblo, Buenos Aires, 20/7/1915, pág. 2. 
legislativa de estas figuras, aquellas que este trabajo ha intentado matizar y complejizar.

El análisis ha permitido establecer que la iniciativa surgió como respuesta de la dirigencia conservadora a la gran huelga que maquinistas y foguistas protagonizaron a comienzos de 1912. La presentación del proyecto de Carlés coincidió con la llegada de Bas y Cafferata a la Cámara de Diputados. A instancias de su participación en la comisión de legislación, el primero de ellos intervino en la evaluación de la propuesta y, posteriormente, desplegó un rol activo en la elaboración de un proyecto alternativo.

La intervención de Bas se inspiró en los principios de la doctrina católica, pero el contenido concreto de su propuesta no estuvo determinado de antemano ni respondió a un plan previamente delineado. Por el contrario, se forjó en el curso mismo de la acción, en la necesidad concreta de responder al conflicto social, articulando sus propias racionalidades y competencias con los sentidos e intereses de un amplio entramado de actores.

Bas promovió un mayor intervencionismo del Estado en las relaciones obrero-patronales y articuló un incipiente lenguaje de derechos orientado a mejorar la situación de los trabajadores. Sostuvo que la jubilación no podía continuar siendo una concesión graciable, sujeta a la voluntad y las condiciones de la patronal. Por tanto, avanzó en el reconocimiento de la jubilación como un derecho social, garantizado por el Estado y destinado a proteger al trabajador en la vejez.

La defensa de una política que institucionalizaba el beneficio jubilatorio y hacía obligatoria la contribución de la patronal generó tensiones con el empresariado. Cosechó, en cambio, el apoyo de los socialistas, quienes ayudaron a definir el contenido del proyecto de la comisión y defendieron la propuesta ante las resistencias empresariales. Esto sugiere que, pese a su discurso invariablemente antisocialista, en su práctica parlamentaria el catolicismo no siempre estableció relaciones de oposición y confrontación con el «partido rojo». Aunque sus diferencias ideológicas moldeaban propósitos y fundamentos distintos, en ocasiones convergieron en el amplio y diverso territorio del reformismo social y establecieron acuerdos en torno a algunas iniciativas específicas.

Pero los católicos no abandonaron su preocupación por el orden social y el tono conservador en lo relativo a las huelgas. Acompañados por la prensa y las asociaciones católicas, Bas y Cafferata promovieron la aprobación del proyecto con el artículo 11 incluido por el Senado. Esto expuso los matices ideológicos que atravesaban al reformismo y abrió paso a la confrontación. Los católicos denunciaron que los socialistas obstaculizaban una ley de protección obrera y estos, a su vez, lanzaron sobre aquellos acusaciones de amarillismo. Las jubilaciones ferroviarias dejaron traslucir una disputa de poder en el campo de la legislación social. Se trataba de liderar la obra legislativa en materia social, pero también de asegurar el predominio de la propia orientación ideológica en ese terreno. En un contexto de democratización en el que el catolicismo se lanzó a «la conquista de las masas", esta disputa también reveló su potencial político para contener el avance de los socialistas y ganar posiciones entre los trabajadores.

En el transcurso de este derrotero, los católicos establecieron articulaciones con dirigentes del radicalismo. Aunque estos vínculos no eran recientes y 
expresaban los propios clivajes ideológicos del partido radical, la posición de figuras como Vicente Gallo y Rogelio Araya contribuyó de manera decisiva a la aprobación de la ley. También contaron con apoyos entre los ferroviarios, particularmente con el sector que demandó la sanción de la ley sin cuestionar el artículo 11.

Este trabajo permitió avanzar tímidamente en la reconstrucción de los vínculos entre Bas y estos trabajadores. Se observó que, en el ámbito parlamentario, el diputado católico apeló a sus peticiones para respaldar sus argumentos y obtener su sanción definitiva, lo que no impide pensar que estos trabajadores encontraron en el diputado católico un representante de sus demandas e intereses. A futuro, se torna imprescindible continuar indagando la dinámica de este vínculo, especialmente durante la puesta en marcha de la Ley 9653, que implicó la sanción de una ley orgánica que regulaba la edad y el monto de los retiros.

En definitiva, los resultados obtenidos sugieren que las jubilaciones ferroviarias no nacieron en el terreno católico, pero se inscribieron en el repertorio de obras legislativas del catolicismo social como resultado de un proceso histórico jalonado de interacciones, acuerdos y conflictos. Esto pone de relieve la importancia de explorar la construcción de las políticas sociales a la luz de las lógicas y los intereses de los agentes del Estado y las presiones y demandas de la sociedad civil.

\section{Bibliografía}

AsquinI, Sabrina (2013). «Los Círculos de Obreros y la cuestión social en la ciudad de Buenos Aires. Una mirada a través de la polémica católico-socialista de 1895». Itinerantes. Revista de Historia y Religión, Tucumán, 3, págs. 133-152.

AuzA, Néstor (1987). Aciertos y fracasos del catolicismo argentino. Buenos Aires: Docencia. BAS, Arturo (1919). Temas institucionales. Córdoba: Los Principios.

Bohoslavsky, Ernesto y SopRano, Germán (comps.) (2010). Un Estado con rostro humano. Funcionarios e instituciones estatales en Argentina (desde 1880 a la actualidad). Buenos Aires: Prometeo.

Camarero, Hernán y Herrera, Carlos Miguel (eds.) (2005). El Partido Socialista en Argentina. Sociedad, política e ideas a través de un siglo. Buenos Aires: Prometeo.

CASTRO, Martín (2011). «Clericalismo político o concentración conservadora: peregrinos/ militantes, caudillos y notables en la formación del Partido Constitucional, 1913-1916». En: Pérez Branda, Pablo (comp.). Partidos y micropolítica. Investigaciones históricas sobre partidos políticos en la Argentina del siglo xx. Mar del Plata: CEHis / Ediciones Suárez, págs. 17-51.

CattaruzzA, Alejandro (2016). Historia de la Argentina 1916-1955. Buenos Aires: Siglo XXI. CHITTI, Juan y AGnelLI, Francisco (1937). Cincuentenario de La Fraternidad. Buenos Aires: Kavaschino Hnos.

D’UvA, Florencia (2018). «Un episodio en la lucha de la reglamentación del trabajo ferroviario: la huelga de maquinistas y foguistas de 1912». TST: Transportes, Servicios y Telecomunicaciones, Madrid, 36, págs. 9-32. 
D’UvA, Florencia (2020). «Las políticas de beneficios de las empresas ferroviarias desde la perspectiva de los trabajadores. Argentina, primeras dos décadas del siglo XX». Notas Históricas y Geográficas, Valparaíso, 24, págs. 132-167.

DI StefANO, Roberto y ZANATTA, Loris (2000). Historia de la Iglesia argentina. Desde la Conquista hasta fines del siglo XIX. Buenos Aires: Mondadori.

FERRARI, Marcela (2008). Los políticos en la república radical: prácticas políticas y construcción de poder (1916-1930). Buenos Aires: Siglo XXI.

FLIER, Patricia (2000). «El desarrollo de la seguridad social en Argentina: los seguros sociales. Del modelo ideal al posible». En: PANETtieRI, José (comp.). Argentina: trabajadores entre dos guerras. Buenos Aires: Eudeba, págs. 119-154.

FreRs, Emilio (1921). Temas diversos, vII. Buenos Aires: Imp. Gadola.

Gordillo, Mónica (1988a). El movimiento obrero ferroviario desde el interior del país (1916-1922). Buenos Aires: CEAL.

GordiLlo, Mónica (1988b). La Fraternidad en el movimiento obrero: un modelo especial de relación (1916-1922). Buenos Aires: Centro Editor de América Latina. Colección Conflictos y Procesos de la Historia Argentina Contemporánea, 20.

IÑIGo CARRERA, Nicolás (2013). «Aproximación al análisis del Centenario como hito en la historia de la confrontación social argentina». PIMSA Documentos y Comunicaciones, Buenos Aires, 14, págs. 69-116.

IsUANI, Ernesto (1985). Los orígenes conflictivos de la seguridad social argentina. Buenos Aires: CEAL.

LEÓN XIII (1960 [1891]). Rerum novarum. Sobre la cuestión obrera. Santiago de Chile: Paulinas.

LIDA, Miranda (2015). Historia del catolicismo en la Argentina: entre el siglo XIX y el XX. Buenos Aires: Siglo XXI.

LIDA, Miranda (2018). «La caja de Pandora del catolicismo social: una historia inacabada». Archivos de Historia del Movimiento Obrero y la Izquierda, Buenos Aires, 13, págs. 13-31.

MARTín, María Pía (2020). Los católicos y la cuestión obrera. Entre Rosario y Buenos Aires (1892-1919). San Martín: Imago Mundi / Ediciones CEHTI.

Ministerio de Obras Públicas (1918). Estadística de los ferrocarriles en explotación, XXI. Buenos Aires: Talleres Gráfico de la Penitenciaría Nacional.

Otero, Hernán (2020). Historia de la vejez en la Argentina (1850-1950). Rosario: Prohistoria.

PAleRmo, Silvana (2004). "Ciencia, reformismo político y los derechos del trabajador-ciudadano: la regulación estatal del trabajo ferroviario según Bialet Masse». Entrepasados, Buenos Aires, 26, págs. 31-52.

PoRTelli, María Belén (2017). «Catolicismo y reforma social en la Argentina a comienzos del siglo xx. Una mirada desde el pensamiento y la obra de Arturo M. Bas». Trashumante. Revista Americana de Historia Social, Medellín / Ciudad de México, 9, págs. 52-77.

RECALDE, Héctor (1985). La Iglesia y la cuestión social (1874-1910). Buenos Aires: CEAL.

SURIANO, Juan (1991). «Estado y conflicto social: el caso de la huelga de maquinistas ferroviarios de 1912». Boletín Ravignani, Buenos Aires, 4, págs. 91-115.

SuRIANO, Juan (comp.) (2000). La cuestión social en Argentina, 1870-1943. Buenos Aires: La Colmena. 
VIDAL, Gardenia (1995). Radicalismo de Córdoba 1912-1930. Los grupos internos: alianzas, conflictos, ideas, actores. Córdoba: UNC.

VIDAL, Gardenia (2006). "Ciudadanía y asociacionismo. Los Círculos de Obreros en la ciudad de Córdoba, 1897-1912». Revista Escuela de Historia, Salta, 5, págs. 25-57.

VIDAL, Gardenia (dir.) (2014). Reseña biográfica de dirigentes que interpelaron el mundo del trabajo en Córdoba 1900-1950. Córdoba: UNC.

ZimmeRmAnN, Eduardo (1995). Los liberales reformistas. La cuestión social en la Argentina 1890-1916. Buenos Aires: Editorial Sudamericana.

Fecha de recepción: 23 de febrero de 2021

Fecha de aceptación: 28 de junio de 2021

Fecha de publicación: 22 de diciembre de 2021 